\title{
The Key Project Managers' Competences for Different Types of Projects
}

\author{
Margarida Dias ${ }^{1}$, Anabela Tereso ${ }^{1}$, Ana Cristina Braga ${ }^{2}$, and A. Gabriela Fernandes ${ }^{1}$ \\ ${ }^{1}$ CGIT Research Centre \\ ${ }^{2}$ ALGORITMI Research Centre \\ School of Engineering, University of Minho \\ 4800-058 Guimarães, Portugal \\ margarida.prdias@gmail.com, \\ \{anabelat, acb,g.fernandes\} @dps.uminho.pt
}

\begin{abstract}
This paper describes a quantitative research approach for identifying key project managers' competences for different types of projects. By identifying the perceived most valuable project manager competences, as having the most potential for increased contribution to project management (PM) performance, practitioners and organizations can select their priorities when developing their PM practices. The 46 competences (technical, behavioural and contextual) provided by IPMA (International Project Management Association) were surveyed through an online questionnaire. Three dimensions to distinguish project types were used: application area, innovation and complexity. Completed questionnaires were received from 96 project managers from Portugal. The results showed that 13 key competences (20\%) were common to the majority of the projects. Most of these are behavioural competences, such as: ethics, reliability, engagement, openness, and leadership. It was also observed a clear correlation between technical competences and project complexity.
\end{abstract}

Keywords: Project management (PM), PM success, Project types, PM competences.

\section{Introduction}

Nowadays we witness an incredible growth of the interest in project management. However, projects continue to fail at a large rate. At the same time, complexity and uncertainty grow in project environments. So, it is time to reflect about how project managers should be educated to deal with projects' complexity and uncertainty growth [10], [16], [23].

The development of project managers' competences in organizations is an important factor to enhance the project management performance and consequently the organization performance [1], [22], [24]. The extent of this impact depends on other factors like the organization context and maturity, or the type of projects [18]. Project types and characteristics were the focus of this research with the objective to associate each type of project to a different group of project managers' competences. 
This challenge came with the knowledge that project managers do their job better and obtain better results when their characteristics and personal competences match with the requirements and needs of the project [9], [14].

Over the years, different Project Management (PM) standards have been developed around the world attempting to codify what is been observed in research and practice [7], [18]. The majority of PM literature continues assuming that all projects are alike, advising organizations to adopt a project management general approach [17], [20].

Different studies showed that a universal approach assuming all projects are the same may not be appropriate to project management [2], [5], [6], [25]. Different types of projects should be managed in different ways. This would suggest that different project managers' competence profiles would be appropriate for different types of projects [11].

Two studies made by Müller \& Turner served as a support for many decisions made in this study and to compare results. A summary of each study is presented next [11], [14].

\section{"Matching the Project Manager's Leadership Style to Project Type" by Müller \& Turner (2007)}

The aim of this research was to show that different leadership styles are more appropriate to reach PM success in different types of projects. To identify the different leadership styles, 15 competences were used (7 emotional, 5 management, and 3 intellectual). To distinguish the different types of projects 6 dimensions were used, two of them were the complexity and the application area. A world wide webbased questionnaire that asked about the type of project, the leadership competences and the project management success, was distributed to project managers.

\section{“Leadership Competency Profiles of Successful Project Managers” by Müller \& Turner (2010)}

Three years later the same authors used the same group of 15 competences to analyse leadership competence profiles of successful project managers in the different types of projects. This time they used 4 dimensions instead of 6 to distinguish the projects by types. The complexity and the application area are again included in these 4 dimensions. The data collection was conducted through a digital questionnaire send to PM professionals around the world.

\section{Research Objectives}

The constant search for the growth of the PM success rate is the base of this study. We believe that project managers' competences influence directly the PM success, and project types affect the degree of that influence. In other words, the importance of each competence in PM success depends on the type of the project [18]. Therefore, the research questions were: What are the key competences of PM that the project managers should have? These competences are different depending on the type of the project? To answer these questions the present research had two objectives: 
A-Find the project managers key competences considering the three dimensions: technical, behavioural and contextual.

B-Check if there is any correlation between a group of project managers' key competences and the different types of projects.

\section{Literature Review}

\subsection{Project Management Success}

The IPMA defines project success as "the appreciation of the various interested parties of the project outcomes". This definition goes far beyond the production of project deliverables within time and budget, considered only a part of the project success [7].

Müller e Turner $(2007,2010)$ use a list of ten project success criteria, extracted from interviews made to managers responsible to assign project managers to projects, with the goal of identifying some correlation between project success and the project managers leadership competences: a) End-user satisfaction with the project product or service; b) Supplier satisfaction; c) Project team satisfaction; d) Other stakeholders' satisfaction; e) Performance in terms of time, cost, quality; f) Meeting user requirements; g) Achieving project purpose; $h$ ) Customer satisfaction with the project results; i) Reoccurring business with the client; j) Meeting the respondents' selfdefined success factors.

It becomes evident that to consider a project successful it is necessary to satisfy a number of requirements that vary from project to project.

In spite of the terms "PM performance" and "project performance" are frequently used indistinctively, the objectives of both PM and project performance are different. PM performance emphasis is towards achieving specific and short-term targets compared to the wider aims of a project [3]. For example, important parameters to project performance will be the return on investment, profitability, competition and market ability, while to project management performance the focus is usually given to the triple constraints, control of time, cost and quality [8], [15]. So, in this study, three dimensions were considered in evaluating the project success: time, budget and client satisfaction.

\subsection{Project Management Competences}

Competence is "a cluster of related knowledge, attitudes, skills, and other personal characteristics that affects a major part of one's job; correlates with performance on the job; can be measured against well-accepted standards; can be improved via training and development; can be down into dimensions of competence." [18]. The three different dimensions of competence defined by PMI in PMBoK are knowledge, performance, and personal characteristics [19].

The third version of ICB (International Competence Baseline) developed by IPMA (International Project Management Association) defines competence as "one collection of knowledge, personal attitudes, skills and relevant experience needed to be successful in a certain function." [7]. The ICB presents, like PMBoK, a division of 
the competences in three different groups: technical competences, contextual competences, and behavioural competences.

This study uses the list of 46 competences provided by ICB: 20 are technical, 11 are contextual, and 15 are behavioural competences (see table 1).

Table 1. Overview of ICB competences

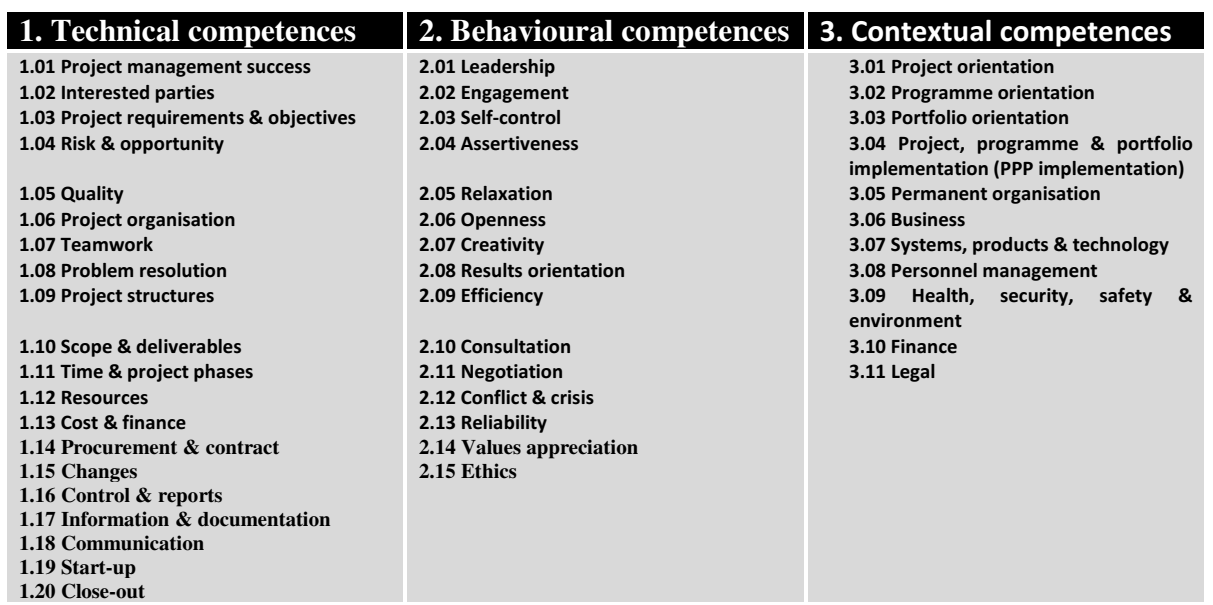

\subsection{Project Types}

In 1978 Blake has suggested a distinction between the minor chance projects (alfa) and major chance projects (beta) [20]. Wheelwright and Clark (1992) differentiated product development projects according to the degree of change in product portfolio. Some have made the distinction between radical and incremental projects [20]. In the work of Turner and Cochrane (1993) is possible to find an increasing understanding of the projects' goals and the methods needed to achieve these goals [20]. The matrices developed by Shennar (2001) use two dimensions, technical uncertainty and project scope [20].

Shennar has several contributions to projects' categorization, some of them with Wideman and others with Dvir. First, they identified three dimensions to distinguish projects: technological uncertainty, complexity and pace [5], [6], [20], [21]. After this identification, they developed the TCP (Technology, Complexity and Pace) model, which had a structure that allowed selecting the best way to manage one project with one certain level of technology, complexity and pace. Some subsequent studies on the validation of the model, proposed one new dimension, the novelty, which defines how new is the product to the potential users, giving rise to a new model with four dimensions: Novelty, Technology, Complexity and Pace (NTCP). Each one of these dimensions is divided in three or four levels, depending on the degree of intensity. In that way, the more complex the project is, the higher will be the level of intensity in the dimension considered. This principle is applied to the four dimensions which are presented in a four axis model. The NTCP model works like a guide to select the project manager, the team members, the structure, the processes and the tools to use in different types of projects [6]. 
In this particular study, projects were distinguished using three different dimensions: application area, complexity, and innovation. Each one of these dimensions has three different levels. The three dimensions and their levels are listed in table 2. The application area was selected because it was found in the two studies of Müller \& Turner presented in the introduction [11], [14], in two other studies by the same authors [12], [13] and in the work by Crawford in 2005 [4]. The complexity was selected because is part of the dimensions used in the two studies, presented in the introduction, by Müller \& Turner, and is part of the NTCP model. Innovation was selected because is one of the dimensions of the NTCP model and because nowadays it is considered important given the continued reduction of product life cycles.

Table 2. Project categorization model used in this study

\begin{tabular}{|l|l|l|}
\hline \multicolumn{1}{|c|}{ Dimension } & \multicolumn{1}{|c|}{ Level/type } & \multicolumn{1}{|c|}{ Reference example } \\
\hline $\begin{array}{l}\text { Application } \\
\text { area }\end{array}$ & $\begin{array}{l}\text { - Engineering \& construction; } \\
\text { - Information, communication \& \& } \\
\text { technology; } \\
\text { - Organizational change. }\end{array}$ & $\begin{array}{l}\text { Crawford, 2005; Müller \& Turner, 2007, } \\
2010\end{array}$ \\
\hline Innovation & $\begin{array}{l}\text { - Breakthrough projects; } \\
\text { - Next generation projects; } \\
\text { - Derivative projects. }\end{array}$ & Dvir, 2006 \\
\hline Complexity & $\begin{array}{l}\text { - Low; } \\
\text { - Medium; } \\
\text { - High. }\end{array}$ & $\begin{array}{l}\text { Dvir, 2006; Müller \& Turner, 2007, 2010; } \\
\text { Shennar, 2001 }\end{array}$ \\
\hline
\end{tabular}

\section{$4 \quad$ Methodology}

It was conducted a web-based survey distributed through the snowball method. This methodology has been found in some similar studies [4], [13], [14]. The target population for this study were the Portuguese project managers. In terms of structure, the questionnaire is divided into four sections:

Project Type. The respondents were asked to categorize the majority of their projects using the three dimensions, choosing only one level in each dimension.

Competence Questions. The 46 competences (Table 1) were listed and project managers were asked to select all the competences they used most in their projects.

PM Success. After a short definition of success that included the three dimensions presented before: time, cost and client requirements, the respondents were asked to judge the majority of their projects as successful or unsuccessful. If the answer was "unsuccessful" another question appeared asking in which of the three dimensions they think they had failed.

Demographic Questions. At the end of the questionnaire the respondents were also asked about the industry sector they worked, their age and gender, how many years they worked in PM, dimension of the company and if they had or not certification in PM. 
The questionnaire release was on July 29, 2013 and the access to the questionnaire was blocked on October 10, 2013. A total of 265 answers were obtained, but only 96 were considered valid (complete answers).

To analyse the existence of some correlation between each of the three types of competences (technical, behavioural and contextual) and each dimension that distinguish projects, three new variables that represent the sum of the competences selected in each group were generated. Then, a non-parametric test (Kruskal Wallis) was conducted, analysing the three new variables in the three dimensions that distinguish projects. For a better comprehension of the results, the following hypotheses were created: H0 (the null hypothesis) - The distribution of the competences (technical, behavioural or contextual) is the same across the categories of each dimension (application area, innovation, or complexity);

H1 (rejection of null hypothesis) - There is a significant difference in the distribution of one or more types of competences (technical, behavioural, or contextual) across the categories of one or more dimension (application area, innovation, or complexity).

A chi-square test of independence was used to verify the existence of an association between the use of the competences and the dimension of the projects considered.

\section{$5 \quad$ Results}

The respondents were predominantly male (76.3\%), aged between 22 and 70 years, and there were more than 50\% with 38 years or less. They had between 1 and 40 years of experience in PM, and almost $59 \%$ had 10 years or less of experience.

Concerning the companies' size, $15.2 \%$ worked in companies with less than 10 employers, $30.4 \%$ in companies with 10 to 49 employers, $35.9 \%$ in companies with 50 to 250 employers and $18.5 \%$ in companies with more than 250 employers. About $12 \%$ of the respondents had some kind of PM certification. Just one of the 96 inquired judged his projects as unsuccessful, pointing the time as the dimension that has failed. In what concerns to project types, relatively to application area, $40 \%$ were engineering and construction projects, $34 \%$ organizational change projects, and $26 \%$ information, communication and technological projects. As for innovation, it was found that $46.6 \%$ were derivative projects, $34.4 \%$ next generation projects, and about $19 \%$ breakthrough projects. In terms of projects complexity, almost $65 \%$ of the projects had medium level of complexity, about $19 \%$ were low complex project and, at last, $16 \%$ of projects had high complexity.

\subsection{Key-Competences for All Projects}

For the evaluation to the most frequent competences used in projects, thirteen competences were found with frequencies higher than $60 \%$ (see table 3 ). 
Table 3. Key-competences for all projects

\begin{tabular}{|l|l|l|}
\hline \multicolumn{1}{|c|}{ Technical } & \multicolumn{1}{|c|}{ Behavioural } & \multicolumn{1}{c|}{ Contextual } \\
\hline $\begin{array}{l}\text { 1. Project management success } \\
\text { (87.5\%); }\end{array}$ & 1. Leadership (74\%); & 1. Programme orientation \\
2. Project requirements and & 3. Openness $(76 \%) ;$ \\
objectives (82.3\%); & 4. Results orientation $(69.8 \%) ;$ \\
3. Problem resolution (63.5\%); & 5. Conflict and crisis $(68.8 \%) ;$ \\
4. Resources (64.6\%); & 6. Reliability (61.5\%); \\
5. Cost and Finance (64.6\%). & 7. Ethics $(76 \%)$. & \\
\hline
\end{tabular}

\subsection{Competences Types vs. Project Types}

The results of the Kruscal Wallis test, and considering a decision rule of 5\% (significance level equal to 5\%), just one rejection of the null hypothesis was found. It happened in the technical competences relatively to the complexity of the projects. So, it was possible to conclude that, at least for this sample, there is a difference in the technical competences due to the projects complexity, or, the projects complexity level has different influence in the utilization of the technical competences.

\subsection{Competences Presence in the Different Project Types}

A chi-square test of independence was used to verify the existence of an association between the use of the competences and the dimension of the projects considered.

Relatively to the application area, five competences with significant differences were found. Three of them were technical and the other two were contextual competences. In organizational change projects, the three technical competences are not very used, on the other hand the two contextual competences seem to be more frequently used by the project managers inquired, that worked in this type of projects, than the project managers that worked in the rest of the application areas.

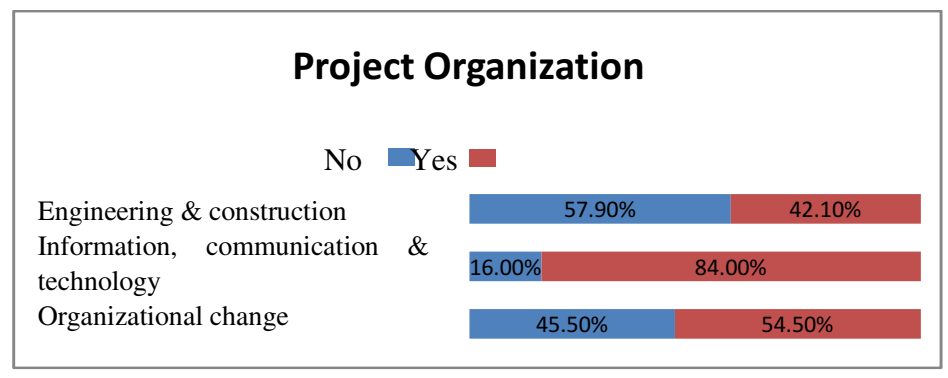

Fig. 1. Distribution of project organization competence responses by application area

Concerning the innovation, the chi-square test reveals that only two competences were found with significant differences, one is technical (close-out) and the other is contextual (programme orientation).

Competences with significant differences were found in the complexity dimension. And, as expected by the results of the Kruskal Wallis test, the higher number of detected differences was in the technical competences (6) in contrast with just one in the behavioural competences. 


\section{Conclusions and Future Research}

\subsection{Conclusions}

The results of this study are discussed comparing its findings with the two similar studies presented before [11], [14].

As explained before, the size of the sample of this study was not enough to allow statistics inferences. However, some of the results of the studies made by Müller and Turner $(2007,2010)$ coincide with some results of this study [11], [14]. The conclusions of that coincidence results are:

1. About $20 \%$ of all PM competences are more important to reach PM success (see table 3);

2. Most of these competences are behavioural, like: Ethics, reliability, engagement, openness, and leadership;

3. The competence of quality is more important to reach the PM success in engineering and construction projects than in other application area projects;

4. The interested parties and the project organization have more influence in PM success in information, communication and technological projects than in the other application area projects;

5. The two contextual competences of programme orientation and business seem to be more important to organizational change projects than to other application area projects;

6. Concerning the medium level complexity projects, three technical competences were identified as the more important ones to the PM success, relatively to the other complexity levels: time and project phases, resources and communication;

7. Analysing projects with high complexity, and comparatively with the other complexity levels, two technical competences stand out: risk and opportunity, and team work;

8. Points 6 and 7 validate the result that sustains the existence of a correlation between the projects' complexity and the technical project managers' competences.

\subsection{Theoretical and Practical Contributions}

Independently of the project type, this study suggests that the development of PM competences, for example through training, should focus more on the behavioural competences than on technical competences, because behavioural competences have a higher influence on PM success.

The present research and its results have more interest to organizations with different project types. Managers that allocate the project managers to projects have to be aware of the importance of the PM competences that the different project types require of their project managers.

Using the three dimensions that distinguish the different project types presented in this study or using other appropriate dimensions, we suggest that organizations identify, in the first place, the types of projects the organization undertakes. Then the organizations should recognize the PM competences needed in each of the project 
types identified. With a good PM competences assessment, it would be easier to allocate the appropriate project managers to the different projects and to identify which competences should be developed.

\subsection{Limitations and Future Research}

The main limitations of this study are related with the sample size and the PM success data collection process, a sample with 96 project managers in one population clearly larger than 1500 Portuguese project managers, is not enough to allow generalizations.

In what concerns to the PM success data collection process, an inaccuracy was made in attempting to reduce the time spent by the respondents answering the questionnaire. Respondents had to indicate whether they considered successful or unsuccessful the majority of their projects. In that way, only 1 out of 96 respondents admitted the majority of his projects to be unsuccessful. If this question has been made in a different way, one association of the competences to the PM success would be possible or better supported.

The suggestions made above lead to the need of future work to develop a PM competences assessment model and identify the best way to develop each competence or type of competence.

Considering the possibility of repeating a similar study, and taking into consideration the limitations presented before, the main suggestion is about the way to collect the data related to the PM success. One good way would be, as was found in the studies made by Müller and Turner (2007, 2010), to present some PM success criteria to the respondents, and he would have to judge their projects, for each criteria, in a Lickert scale with five points [11], [14]. This process would be repeated so project managers could judge each PM success criteria in terms of importance to achieve the PM success. In that way, the association between the PM success and the PM competences would be much more supported. It would also be possible to associate one specific PM competence to the success of one project type and to the failure of other project types.

\section{References}

1. Andersen, E.S., Vaagaasar, A.L.: Project Management Improvement Efforts-Creating Project Management Value By Uniqueness or Mainstream Thinking? Project Management Journal 40(1) (2009)

2. Balachandra, R., Friar, J.H.: Factors for success in R\&D projects and new product innovation: A contextual framework. IEEE Transactions on Engineering Management 44(3), 276-287 (1997)

3. Cooke-Davies, T.J.: Towards Improved Project Management Practice: Uncovering the Evidence for effective practices through empirical research. Leeds Metropolitan University. Thesis for Doctor Philosophy (2001)

4. Crawford, L., Hobbs, B., Turner, R.: Project Categorization Systems. Four Campus Boulevard Newton Square. Project Management Institute, Inc., Pennsylvania (2005)

5. Dvir, D., Lipovetsky, S., Shennar, A.J., Tishler, A.: In search of project classification: A non-universal approach to project success factors. Research Policy 27, 915-935 (1998) 
6. Dvir, D., Sadeh, A., Malach-Pines, A.: Projects and Project Managers: The Relationship Between Project Managers' Personality, Project Types, and Project Success. Project Management Journal 37(5), 36-48 (2006)

7. IPMA. IPMA Competence Baseline - Versão 3.0 (2006)

8. Jha, K.N., Iyer, K.C.: Commitment, coordination, competence and the iron triangle. International Journal of Project Management 25(5), 527-540 (2007)

9. Madter, N., Bower, D.A., Aritua, B.: Projects and personalities: A framework for individualising project management career development in the construction industry. International Journal of Project Management 30(3), 273-281 (2012)

10. Mengel, T.: Outcome-based project management education for emerging leaders - A case study of teaching and learning project management. International Journal of Project Management 26, 275-285 (2008)

11. Müller, R., Turner, J.: Matching the project manager's leadership style to project type. International Journal of Project Management 25, 21-32 (2007a)

12. Müller, R., Turner, J.: The Influence of Project Managers on Project Success Criteria and Project Success by Type of Project. European Management Journal 25 (2007b)

13. Müller, R., Turner, R.: Attitudes and leadership competences for project success. Baltic Journal of Management 5(3), 307-329 (2010a)

14. Müller, R., Turner, R.: Leadership competency profiles of successful project managers. International Journal of Project Management 28(5), 437-448 (2010b)

15. Munns, A.K., Bjeirmi, B.F.: The role of project management in achieving project success. International Journal of Project Management 14(2), 81-87 (1996)

16. Ojiako, U., Ashleigh, M., Chipulu, M., Maguire, S.: Learning and teaching challenges in project management. International Journal of Project Management 29(3) (2011)

17. Papke-Shields, K.E., Beise, C., Quan, J.: Do project managers practice what they preach, and does it matter to project success? International Journal of Project Management 28(7), 650-662 (2010)

18. PMI. Project Management Competency Development (PMCD) Framework, 2nd edn. Project Management Institute, Inc., Newtown Square (2007)

19. PMI. A Guide to the Project Management Body of Knowledge, 4th edn. Project Management Institute, Inc., Newtown Square (2012)

20. Shennar, A.J.: One size does not fit all projects: exploring classical contingency domains. Management Science 47(3), 394-414 (2001)

21. Shennar, A.J., Bonen, Z.: A new taxonomy os systems: Toward an adaptive systems engineering framework. IEEE Transactions on Systems, Man, and Cybernetics 27(2), 137145 (1997)

22. Shi, Q.: Rethinking the implementation of project management: A Value Adding Path Map approach. International Journal of Project Management 29(3) (2011)

23. Thomas, J., Mengel, T.: Preparing project managers to deal with complexity - Advanced project management education. International Journal of Project Management 26, 304-315 (2008)

24. Thomas, J., Mullaly, M.: Researching the value of project management. Project Management Institute, Inc., Newtown Square (2008)

25. Tishler, A., Dvir, D., Shennar, A., Lipovetsky, S.: Identifying critical factors of defense development projects: A multivariate analysis. Technological Forecasting and Social Change 51, 151-171 (1996) 